\title{
Commentary
}

\section{Warring ants: Lessons from Lanchester's laws of combat?}

For which of you, intending to build a tower, sitteth not down first, and counteth the cost, whether he have sufficient to finish it?

Lest haply, after he hath laid the foundation, and is not able to finish it, all that behold it begin to mock him,

Saying, This man began to build, and was not able to finish.

Or what king, going to make war against another king, sitteth not down first, and consulteth whether he be able with ten thousand to meet him that cometh against him with twenty thousand?

Luke, 14: 28-30

F W Lanchester (1868-1946) was a man of many talents. This British engineer not only built the first car in Britain in 1895, but made significant contributions to aeronautics (e.g. the Lanchester-Prandtl general equations of flight), operations research and military strategy. In fact, there is an annual prize offered in his name by the Operations Research Society of America. But perhaps, more importantly, Lanchester is remembered for his insights into military tactics. His book Aircraft in Warfare: the Dawn of the Fourth Arm written in 1916 just before World War I laid down laws of combat which involved insights using force strengths in terms of numbers, fighting capabilities of individual soldiers or weapons, and the concentrations of forces. Lanchester considered aircraft as a fourth type of military force after cavalry, infantry and artillery and hence the title of his book.

Lanchester divided warfare into two basic types: ancient and modern. Of the former type he says: In olden times, when weapon directly answered weapon, the act of defense was positive and direct, the blow of sword or battle-ax was parried by sword and shield. Under the old conditions, it was not possible by any strategic plan or tactical maneuver to bring other than approximately equal numbers of combatants into the actual firing line; one man would ordinarily end himself opposed by one man. Even were a general to concentrate twice the number of men on any given portion of the field to that of the enemy, the number of men actually wielding their weapons at any given time, was, roughly speaking, the same on both sides (Lanchester 1916).

Based on this line of reasoning, Lanchester came up with a Linear Law of combat which says that the chances of winning depend therefore not so much on numbers of attacking units but more importantly on the effectiveness of each attacking unit especially if the battle is actually composed of a series of duels. This is how the Lanchester Linear Law may be derived. Let $m$ and $n$ be the numbers of opposing forces $M$ and $N$ at time $t$. Let $\beta$ and $\alpha$ be the fighting ability of one unit of force $M$ and $N$. The rate of attrition of the two sides is calculated as: $d m / d t=-\alpha m$ and $d n / d t=-\beta m$ (where $m<n$ ). Therefore $d m / d n=\alpha / \beta, d m=(\alpha / \beta) d n$, and $\beta d m=\alpha d n$. Integrating from time 0 to time $t, \beta\left(m-m_{0}\right)=$ $\alpha\left(n-n_{0}\right)$. When side $M$ wins, $n=0$. Therefore, $m=m_{0}-\alpha / \beta\left(n_{0}\right)$. Consequently, side $M$ will win if $m_{0}$ $>\alpha / \beta\left(n_{0}\right)$. This means that if $m_{0}=n_{0}$ to begin with, then side $M$ can only win if the fighting ability of each unit of $M$ is greater than that of each unit of $N$. This is a straightforward commonsensical result if the battle is set up as a set of duels.

Lanchester then dealt with combat situations that he likened to modern warfare. In this case every unit of side $M$ can inflict damage on every unit of side $N$ at the same time, which means that a concentration of forces will be a much better strategy. For example, in the earlier linear situation of duels, arraying 100 attacking units against 50 units would not have any particular advantage. However, in a modern warfare context, concentrating 100 units against 50 would be a decided advantage as each unit of the enemy force would be attacked by two units of the other side. In 
situations such as these, could a smaller force win over a larger force? This could be achieved if the smaller force divided up the larger force by tactical manoeuvres into two parts and then concentrated its attack on each part separately. To derive the rate of attrition according to the conditions of modern warfare, similar equations apply. Here, $d m / d t=-\alpha n$, and $d n / d t=-\beta m$. Therefore, $d m / d n=(\alpha / \beta) n / m$, which leads to $m d m=(\alpha / \beta) n d n$. Integrating this from time 0 to time $t, m^{2}-m_{0}^{2}=(\alpha / \beta) n^{2}-n_{0}^{2}$. When side $M$ wins, $n=0$. Rearranging, $m^{2}=m_{0}^{2}-(\alpha / \beta) n_{0}^{2}$. Therefore, $m=\sqrt{ }\left(m_{0}^{2}-\alpha / \beta n_{0}^{2}\right)$. This is Lanchester's Square Law. On examination of this law it can seen that for side $M$ to win, the condition $m_{0}>(\alpha / \beta) n_{0}^{2}$ must apply. This means that even if each unit of side $N$ has 25 times or $\alpha / \beta$ times the fighting value of each unit of side $M$, side $M$ has merely to have 5 times or $\sqrt{ }(\alpha / \beta)$ times the number of attacking units of side $N$ to match the fighting strength of side $N$. This is an important result with predictive value if $\alpha / \beta$ is known.

What about the strategy in which the smaller side divides up the larger side and then concentrates on smaller enemy subsets sequentially? A famous example is Nelson's strategy at Trafalgar. In the Battle of Trafalgar (21 October 1805), Lord Nelson won a famous victory over the combined French and Spanish fleets. Nelson split the enemy fleet into two using a small subset of his fleet; then the larger subset engaged the two portions of the enemy fleet separately. This ended in the capture of 20 enemy ships by the English. Was this a lucky accident or the outcome of a carefully planned strategy? Apparently this was a premeditated ploy (Franks and Partridge 1994). In a memo Nelson wrote on 9 October 1805, he assumed that his entire fleet of 40 ships would encounter the larger French and Spanish fleet consisting of 46 ships. He decided that he would use 8 ships to split the enemy fleet into two sections; he would then use his remaining 32 ships to destroy the first half of the fleet, and engage the second half later. He thus felt that he would be able to increase his odds of destroying a greater proportion of the enemy fleet. In retrospect, it appears as if Nelson was using Lanchester's Square Law of combat. If the fighting ability of each combat unit of the two warring sides was equal, then applying Lanchester's Square Law, the French and Spanish fleet could be expected to win with 23 survivors $\left[\sqrt{ }\left(46^{2}-40^{2}\right)\right]$. However if Nelson employed 8 ships to split the enemy fleet into two equal parts, the English would have been left with 22 surviving ships $\left[\sqrt{ }\left(32^{2}-23^{2}\right)\right]$. This figure could also be augmented by any survivors of the initial 8 ships; Nelson would thus increase his odds of winning the overall battle over those calculated by simultaneously pitting the two entire fleets against each other. History proved him right.

Lanchester's Square Law can further be used to show that if the number of combat units or combatants is doubled by splitting each into a unit half the size, so that each combat unit now has half its original fighting ability, then the number of casualties suffered by the now more numerous side is proportionately lowered. Thus a disproportionately greater benefit will be obtained by increasing numbers of combat units than by simply increasing the fighting ability of each combat unit, if all combat units have equal probability of being engaged with all enemy combatants at the same time. The essence of the Lanchester's two laws of combat appears to be that small combat units can be highly successful if they are greatly in the majority and if they encounter the larger units all at once. However, if large combat units are greatly outnumbered by smaller units, they can be successful only if they engage the smaller ones in a series of one-to-one fights.

Lanchester's strategies are used in planning several real war games and tactics for deploying forces as they lend themselves to precise predictions. They are apparently also being used successfully in Japanese business and marketing strategies, an effort that has been pioneered by Nobuo Taoka (Taoka 1997). These marketing strategies employ terms such as "local battles", "close combat", and "onepoint concentration" in their lexicon (Yano 1996), and focus on offensive and defensive strategies of the weak and the strong. For example, advice given to the weak is to fight in only one market, i.e. to concentrate forces, and to differentiate to produce better products. The corresponding defensive strategies of the strong would be to take the combat to large markets to swamp the offensive efforts of the weak, to the extent of even flooding the market with copycat products as soon as possible. Although these are qualitative descriptions, they have been refined into quantitative prescriptions (Taoka 1997). This view of business as war has apparently contributed to the success of Japanese business and marketing strategies in the post-World War II scenario. Curiously, Taoka was apparently inspired by the use of Lanchester's laws by the US Navy against the Japanese in the Pacific war arena. 
Since competition and therefore some form of combat, is part of the fabric of life, it would be interesting to examine how other species organize their battles. For example, do warring ants follow Lanchester's laws? Army ants capture and overpower organisms many times their size. They appear to do so by sheer numbers. In the army ant Eciton burchelli up to 200,000 ants participate in a single raid; however, although $E$. burchelli has four morphological castes, the two smallest castes account for $97 \%$ of the ants at the raid front (Franks 1982). This would be expected by Lanchester's Square Law as the large numbers of small ants are highly effective. In an experimental study of war games in leaf cutting ants, Whitehouse and Jaffe (1996) found that although Atta laevigata has a "soldier" caste which is much larger in size, this caste recruits large numbers of smaller castes in response to conspecific and interspecific ant threats, in accordance with the Square Law. The functional significance of the soldier caste in this species is not yet clearly understood.

Lanchester's Linear Law appears to be followed in slave-making ants which steal brood from heterospecific colonies to augment the worker force in their own nests. The slave-makers are usually outnumbered by workers in the colonies that they wish to raid. Do the slave-makers try to organize one-to-one duels? According to Franks and Partridge (1993) the slave-making ants Formica pergandei and F. subintegra which produce "propaganda" or confusing substances (esters such as decyl, dodecyl and tetradecyl acetates) that cause alarm amongst the defending workers (Regnier and Wilson 1971), are actually trying to split the enemy ranks to force limited engagements or one-to-one duel situations. In these duels, victory is ensured by the superior individual fighting ability of the slavemaking ants, many of which are equipped with powerful mandibles and stings. Another possible example of the use of the Linear Law is the slave-making ant Harpagoxenus sublaevis which produces the "propaganda" alkanes $n$-heptadecene and $n$-heptadecadiene (Ollet et al 1987) that cause the defenders to attack each other (Allies et al 1986).

In a recent experiment, McGlynn (2000) attempted to test whether ants use Lanchester's laws in interspecific competition at food sources. He designed two types of bait platforms, and conducted these experiments in natural settings at the La Selva Biological Station in Costa Rica. In one bait platform (modified petri dishes), he had large semicircular openings which provided access to the bait, while the other had a narrow entrance which provided bait access. McGlynn found that, although ants of all sizes were attracted to the baits, smaller ant species significantly dominated the bait platforms that has large entry access holes, while there was no clear pattern of domination by ants of any particular size at the platforms with the small entry holes. McGlynn (2000) suggests that these results may be interpretable from Lanchester's laws, at least for the results from the smaller ants. However, he does caution that other factors such as territoriality, nutritional needs of the colony, nest locations, and the suite of competing species near particular bait platform sites, could have contributed to the findings. Considering the very significant result obtained with the bait platforms provided with the large openings, McGlynn (2000) suggests that this could be used to design baits platforms to administer insecticides for ant control, especially since the problem ants worldwide seem to be small non-native invading species (McGlynn 1999). In a comparative study, McGlynn (1999) found that in all of the ant genera with monomorphic worker castes that fight during competition, the non-native invasive species were smaller than the native species. He believes that the fact that fighting nonnative ants are smaller than their closest native relatives may provide powerful insights into the mode of success of the non-native invading species. While other factors including life history attributes such as polygyny and colony budding, could be responsible for their competitiveness, it is certainly intriguing to consider whether some of this success could be attributed to the fact that the ants are following Lanchester's laws of combat.

\section{References}

Allies A B, Bourke A F G and Franks N R 1986 Propaganda substances in the cuckoo ant Leptothorax kutteri and the slave-maker Harpagoxenus sublaevis; J. Chem. Ecol. 12 1285-1293

Franks N R 1982 Ecology and population regulation in the army ant Eciton burchelli; in The ecology of a tropical forest (eds) E G Leigh, A S Rand and D M Windsor (Washington DC: Smithsonian) pp 389-395

Franks N R and Partridge L W 1993 Lanchester battles and the evolution of combat in ants; Anim. Behav. 45 197-199 
Franks N R and Partridge L W 1994 Lanchester's theory of combat, self-organization, and the evolution of army ants and cellular societies; in Behavioral mechanisms in evolutionary ecology (ed.) L A Real (Chicago: University of Chicago Press) pp 390-408

Lanchester F W 1916 Aircraft in warfare - the dawn of the fourth arm (London: Constable)

McGlynn T P 1999 Non-native ants are smaller than related native ants; Am. Nat. 154 690-699

McGlynn T P 2000 Do Lanchester's laws of combat describe competition in ants?; Behav. Ecol. 11 686-690

Ollet D G, Morgan E D, Attygalle A B and Billen J P J 1987 The contents of the Dufour gland of the ant Harpagoxenus sublaevis Nyl. (Hymenoptera: Formicidae); Z. Naturforsch. Teil A 42c 141-146

Regnier F E and Wilson E O 1971 Chemical communication and "propaganda" in slave-maker ants; Science 172 267-269

Taoka N 1997 Lanchester strategy: an introduction (Sunnyvale, California: Lanchester Press)

Whitehouse M E A and Jaffe K 1996 Ant wars: combat strategies, territory and nest defence in the leaf-cutting ant Atta laevigata; Anim. Behav. 51 1207-1217

Yano S 1996 New Lanchester strategy - sales and marketing strategy for the weak Vol 2 (Sunnyvale, California: Lanchester Press)

RENEE M BORGES

Centre for Ecological Sciences,

Indian Institute of Science,

Bangalore 560 012, India

(Email,renee@ces.iisc.ernet.in) 